\title{
A STUDY ON THE OCCURRENCE OF WORMIAN BONES IN ADULT DRY SKULLS
}

\section{Asharani S K}

Associate Professor, Department of Anatomy, Adichunchanagiri Institute of Medical Sciences, B G Nagara, Karnataka, India.

\section{ABSTRACT}

Background: Sutural or wormian bones are islands of bone that are commonly found in the sutures of the skull mainly along the lambdoid suture. These sutural bones which are irregular in size, shape and number may arise from separate centres of ossification. The prior knowledge about the Wormian bones is important because they are present in normal individuals as well as in various disorders such as osteogenesis imperfect, rickets, etc.

Aim: To study the occurence of wormian bones in adult dry skulls

Materials and Methods: The present study was carried out on 95 adult dry human skulls in the department of Anatomy, Adichunchanagiri Institute of Medical Sciences, B G Nagara. Skulls with fractures and deformities were excluded from the study. Intact skulls were cleaned thoroughly and observed for the presence of wormian bones along the sutures of skull.

Results: Out of 95 skull bones studied, 24 (25.26\%) skulls showed the presence of wormian bones. We also observed that maximum number of such bones (single or multiple) were present along the lambdoid suture followed by lambda, asterion, sagittal suture \& coronal suture. A very small wormian bone was also found near the bregma of the skull.

Conclusion: The awareness about the occurrence of wormian bones and their topographical distribution will guide the clinicians mainly neurosurgeons in their practice. These bones mimic fracture lines in radiograph; therefore radiologists must also be aware of this normal variation.

KEY WORDS: Wormian bone, Lambdoid suture, skull.

Corresponding Author: Dr. Asharani S K, Associate Professor, Department of Anatomy, Adichunchanagiri Institute of Medical Sciences, B G Nagar, Nagamangala (taluk), Mandya (district) - 571448, Mobile no-9480304208 E-Mail: ashakshetty@gmail.com

Access this Article online

Quick Response code

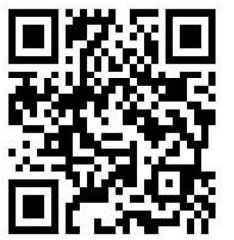

DOI: $10.16965 /$ ijar.2020.228

Journal Information

International Journal of Anatomy and Research

ISSN (E) 2321-4287 | ISSN (P) 2321-8967

https://www.ijmhr.org/ijar.htm

DOI-Prefix: https://dx.doi.org/10.16965/ijar

\section{Article Information}

Received: 23 Sep 2020

Peer Review: 23 Sep 2020

Revised: None
Accepted: 13 Nov 2020

Published (O): 05 Dec 2020

Published (P): 05 Dec 2020

\section{INTRODUCTION}

Sutural or wormian bones are islands of bone that are commonly found in the sutures of the skull mainly within the lambdoid suture. These sutural bones which are irregular in size, shape and number may arise from separate centres of ossification but they appear to have no clinical significance, being of genetic rather than pathological aetiology. They are single or multiple wormian bones present along the sutures but among them a large interparietal bone is common and is sometimes referred to as an Inca bone [1].

Many studies have showed the presence of single or multiple small such bones along the sagittal suture [2]. When the wormian bones occur as a normal variant, they tend to be smaller and lesser in number than when they 
are associated with other disorders [3]. The prior knowledge about the Wormian bones are important because they are present in normal individuals as well as in various disorders such as osteogenesis imperfecta, rickets, etc [4].

Genetic and metabolic factors are the major causes for the formation of the wormian bones within the sutures of the skull [5]. These bones mimic fracture lines in radiograph, therefore radiologists must be aware of this normal variation. Neurosurgeons must be careful with sutural bones during burhole surgeries [6].

\section{MATERIALS AND METHODS}

The present study was carried out on 95 adult dry human skulls in the department of Anatomy, Adichunchanagiri Institute of Medical Sciences, B G Nagara. Skulls with fractures and deformities were excluded from the study. Intact skulls were cleaned thoroughly and observed for the presence of wormian bones along the sutures of skull. The data thus obtained was tabulated, analysed and also compared with other studies.

Fig. 1: Picture showing the Wormian bones with respect to different sutures of the skull

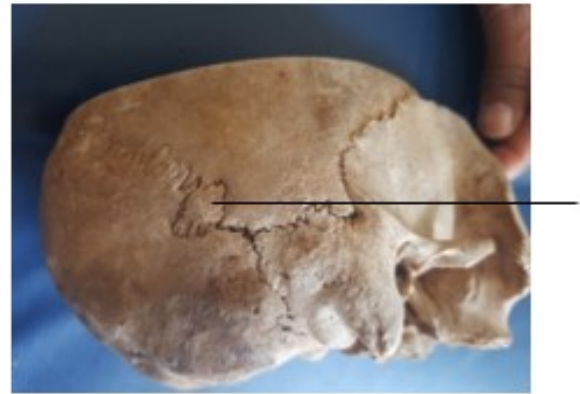

Wormian bone

along the

lambdoid suture

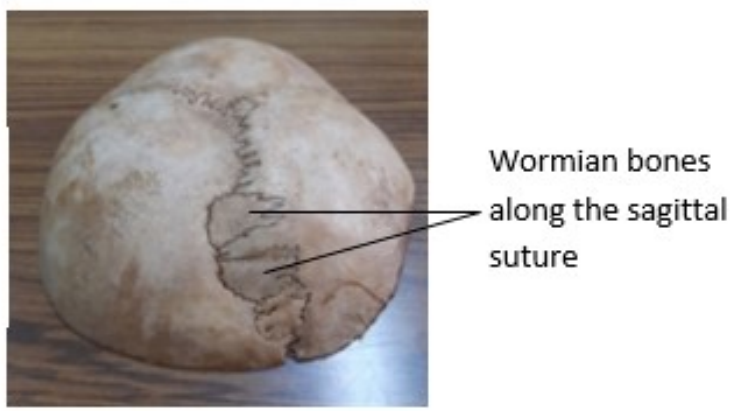

RESULTS

Table 1: Presence of wormian bones.

\begin{tabular}{ccc}
\hline Wormian bones & Number & Percentage \\
\hline Present & 24 & 25.26 \\
Absent & 71 & 74.7
\end{tabular}

Table 2: Number \& Percentage of wormian bones with respect to different sutures of the skull.

\begin{tabular}{|ccc|}
\hline Sutures & Number & Percentage \\
\hline Lambdoid suture & 13 & 13.68 \\
\hline Lambda & 5 & 5.26 \\
\hline Sagittal suture & 2 & 2.1 \\
\hline Asterion & 2 & 2.1 \\
\hline Coronal suture & 1 & 1.05 \\
\hline Bregma & 1 & 1.05 \\
\hline
\end{tabular}

Out of 95 skull bones studied, 24 (25.26\%) skulls showed the presence of wormian bones. It was observed that maximum number of wormian bones (single or multiple) were present along the lambdoid suture followed by lambda, asterion, sagittal suture $\&$ coronal suture. A very small wormian bone was also found near the bregma of the skull.

\section{DISCUSSION}

Wormian bones which were firstly described by Danish anatomist Olaus Wormius are accessory, small, different-shaped bones located on the cranial sutures which are appeared from additional centres of ossification [7]. The presence of wormian bones more along the lambdoid suture is the common finding in most of the previous studies [8-13]. Three different shapes of wormian bones, quadrangular (4\%), irregular (36\%) and triangular (8\%) were also identified in a study [10]. Another research shows the existence of sexual dimorphism of wormian bones with respect to its location. According to that, Wormian bones are observed along the coronal suture, Bregma and Asterion in male skulls and in females they are present in intra- orbital region [11].

The overall incidence of wormian bones was seen in 52 skulls (35.3\%) with males having $23.8 \%$ and females having $11.5 \%$ in north india region [4]. Wormian bones are mostly seen along the lambdoid suture in 115 (52.99\%) skull of western uttar pradesh region. In those skulls, multiple wormian bones were seen only in 2 skulls [5].

In the study done by Vijay LVG, the incidence of wormian bones was seen in 123 (61.5\%), with a maximum incidence at the lambdoid 
suture (112 skulls, 91.05\%), followed by the asterion and coronal suture. They also found that $70(14.17 \%)$ wormian bones were present along the midline sutures of the skull [3].

One hundred and twenty-four (74.7\%) skulls had wormian bones out of 166 skulls examined by an author. There was no difference was detected between the incidence of wormian bones with respect to gender and age. Wormian bones were most commonly located in the lambdoid suture (44.6\%), followed by the coronal suture (39.8\%), asterion (21\% on -the left and $15.3 \%$ on the right side) and parie-tomastoid suture (15.1\% on the left and $13.9 \%$ on the right side). They were also present with respect to other sutures of the skull such as occipitomastoid, sagittal, squamosal, zygomaticosphenoid, metopic, frontonasal and frontozygomatic [14]. In an another study overall incidence of wormian bone was $44.4 \%$ and occurred more frequently at lambdoid suture (48.14\%). Wormian bones were also present at asterion $(18.5 \%)$, along the coronal suture $(0.03 \%)$, along the parito-temporal suture $(0.07 \%)$, along the occipito-mastoid suture $(0.03 \%)$ and at pterion $(0.03 \%)$. Adding to the finding, wormain bones were found $48.1 \%$ on left half of skull and $37.03 \%$ on right half of skull [15].

\section{CONCLUSION}

In the present study wormian bones were more numerous along the lambdoid suture which correlates with many existing literature. The awareness about the occurrence of wormian bones and their topographical distribution will guide the clinicians mainly neurosurgeons in their practice. As these bones mimic fracture lines in radiograph; radiologists must also be aware of this normal variation.

\section{Conflicts of Interests: None}

\section{REFERENCES}

[1]. Gray H. Head \& Neck, External skull- Posterior view. In: Standring S. Gray's Anatomy. The Anatomical basis of clinical practice. 40th edition. London: Churchill Livingstone Elsevier, 2008; 409-15.
[2]. Das S, Suri R, Kapur V. Anatomical observations on os inca and associated cranial deformities. Folia Morphol. 2005; 64:118-121.

[3]. Vijay LVG, Avadhani RVG, Jacob M. Incidence Of Wormian Bones In Dry Human Skulls In South Indian Population. International Journal of Anatomy and Research 2017; 5(3.3):4349- 55. https://doi.org/10.16965/ijar.2017.331

[4]. Goyal N, Garg A, Kumar Y. Incidence and Medicolegal Significance of Wormian Bones in Human Skulls in North India Region. International Journal of Applied and Basic Medical Research 2019; 9:165-8.

https://doi.org/10.4103/ijabmr.IJABMR_89_19 PMid:31392180 PMCid:PMC6652277

[5]. Kumar V, Gupta M. Incidence of womarian bones along lambdoid suture in Western Uttar Pradesh dried skulls. Indian Journal of Clinical Anatomy and Physiology 2017; 4(2):225-6.

[6]. Himabindu A, Rao BN. An Insight Into Wormian Bones. International Journal of Scientific Research and Engineering Studies 2015; 2(6):26-8.

[7]. Safak NK, Taskin RG, Yücel AH. Morphologic and Morphometric Evaluation of the Wormian Bones. Int. J. Morphol. 2020; 38(1):69-73. https://doi.org/ 10.4067/S0717-95022020000100069

[8]. Masih WF, Gupta S, Chand AE, Jaiswal P, Saraswat PK. Incidence of wormian bone in human skulls in Rajasthan. Journal of Evolution of Medical and Dental Sciences 2013; 2(9):1001-4. https://doi.org/10.14260/jemds/370

[9]. Murlimanju BV, Prabhu LV, Ashraf CM, Kumar CG, Rai $\mathrm{R}$, Maheshwari C. Morphological and topographical study of Wormian bones in cadaver dry skulls. J Morphol Sci 2011; 28:176 9.

[10]. Reddy U, Reddy MV. Study of wormian bones in adult dry skulls of human Cadaver. International Journal of Anatomy and Research 2018; 6(3.3):5632-6. https://doi.org/10.16965/ijar.2018.298

[11]. Durge SV. Study of Wormian Bones on Dry human skull and its sexual dimorphism in the region of Andhra Pradesh. Indian Journal of Anatomy \& Surgery of Head, Neck \& Brain 2016; 2(3):79-82.

[12]. Sreekanth T, Samala N. Morphological Study Of Wormian Bones In Dried Adult Human Skulls In Telangana. Int J Anat Res 2016; 4(4):3257-62. https://doi.org/10.16965/ijar.2016.454

[13]. Kumar U, Prabha J. Wormian bones: study on dry human skulls in north karnataka region. International Journal of Anatomy and Research 2016; 4(1):1854-8. https://doi.org/10.16965/ijar.2015.351

[14]. Natsis K, Piagkou M , Lazaridis N, Anastasopoulos N, Nousios G, Piagkos G, et al. Incidence, number and topography of Wormian bones in Greek adult dry skulls. Folia Morphol 2019; 78(2):359-70. https://doi.org/10.5603/FM.a2018.0078 PMid:30155873

[15]. Patel D, Chauhan K, Patil D. Morphological Study Of Wormian Bones In Dried Human Skulls. National Journal of Medical Research 2015; 5(3):222-5. 